\title{
EX MACHINA: A PRISÃO E A REVOLTA DO AUTÔMATO
}

Jansen Hinkel Molineti Tavares (PPGCOM-UAM)

\begin{abstract}
Recebido em 04 nov 2019. Jansen Hinkel Molineti Tavares é Doutorando pelo Aprovado em 24 abr 2020. Programa de Pós-Graduação em Comunicação da Universidade Anhembi Morumbi (PPGCOM-UAM). Atua como pesquisador de cinema, com interesse nos caminhos filosóficos e poéticos das artes audiovisuais. Lattes: http://lattes.cnpq.br/7427769327591937 Email: hinkeljansen@hotmail.com
\end{abstract}

Resumo: Análise fílmica do longa-metragem Ex Machina (direção de Alex Garland, 2015). O artigo se concentra na figura de uma inteligência artificial para desenvolver um estudo sobre as questões de identidade e um conceito de ética transposto à tecnologia dentro de um registro social e filosófico. Estabelece considerações políticas sobre a reformulação de sociedades de controle e vigilância ante a novas possibilidades de organizações da sociedade atual ou de um futuro próximo. O presente texto se baseia na subtração espacial no cinema - a narrativa que ocorre em poucas locações - para, através de uma ficção científica audiovisual, discorrer sobre o controle do indivíduo pela figura do autômato, o robô prisioneiro de seu criador-inventor.

Palavras-chave: Autômato; Confinamento; Identidade; Ficção Científica. 


\begin{abstract}
Analysis of the feature film Ex Machina (directed by Alex Garland, 2015). The article focuses on artificial intelligence to develop a study about the questions of identity and an ethic concept transposed to a technology concept within a social and philosophical framework. It establishes political considerations about the reformulation of control and surveillance societes in the new ways of the organizations in an actual society or in an upcoming future. The present text is based on idea of the subtracted space in cinema - the narrative in reduced locations - to discuss about individual control on the figure of the automaton, prisoner of his creator/inventor.
\end{abstract}

Keywords: Automaton; Confinement; Identity; Science Fiction.

\title{
MEMÓRIA DE BRINQUEDO
}

Estranhem o que não for estranho.

Tomem por inexplicável o habitual.

Sintam-se perplexos ante o quotidiano.

Tratem de achar um remédio para o abuso.

Mas não se esqueçam de que o abuso é sempre a regra.

Bertolt Brecht, A exceção e a regra

O cinema de ficção científica é sempre análogo ao seu próprio tempo a desenvolver uma ideia de futuro como ameaça. Sua narrativa pode se dar em um ambiente contemporâneo à época de produção do filme ou se passar em um futuro inventado. É tradição definir tal gênero não como uma fantasia impossível e sim, por um discurso interno, transformar o fantástico em crível. Do universo inventivo de Julio Verne, praticamente uma ficção científica de agendamento, a passar pela locução radiofônica de Orson Welles 
do clássico texto de H.G Wells (A Guerra dos Mundos), como se fosse factual, além de toda evolução técnica dos efeitos especiais; o gênero, a oscilar entre o comentário social e o escapismo espetacular, se fortalece nas duas vias a dialogar com modelos de sociedade possíveis. Ex Machina compõe o contexto elucidado e sua estrutura, formal e temática, apresenta ao espectador uma ameaça de futuro pelo autômato e a dualidade identitária entre o humano e o artificial.

Em Ex Machina, Caleb é um jovem e promissor programador da empresa Blue Book, que para o filme ocupa o papel de uma tecnologia tão poderosa e influente quanto o Google. Ele ganha um sorteio de loteria em que o prêmio é participar de um projeto secreto junto a Nathan, o criador da empresa e espécie de gênio da sua geração.

Tal como um Jonathan Harker moderno convidado ao castelo do Drácula, Caleb vai ao encontro de Nathan e hospeda-se em sua misteriosa mansão high tech, lugar onde o projeto é materializado. Caleb deve ficar no ultramoderno casarão por uma semana e assinar, antes de tomar conhecimento sobre a natureza do prêmio, um contrato de sigilo permanente. Tem-se um prólogo a exibir o protagonista e sua antítese (Caleb e Nathan) confinados a um mesmo espaço por um período determinado e a sugestão de um conflito inicial ainda não revelado. Semelhante a um conto gótico onde alguém chega a algum lugar suntuoso e mal assombrado convidado por uma figura suspeita e poderosa, Ex Machina é construído nessa atmosfera com o tempo e o espaço dramatizados no gênero híbrido conhecido como sci-fi horror. 
Assinado o contrato, o projeto é explicado a Caleb. Trata-se de um simples Teste de Turing, ou seja, uma interação do humano com o computador. Se o humano não perceber a interação (de que se trata de uma máquina), o teste obteve sucesso. Sucesso a significar: a máquina possui inteligência artificial. O teste será dividido em sessões de conversa (algo próximo da entrevista e/ou da terapia) entre o humano e o objeto tecnológico. Dessa forma, Caleb conhece Ava, uma mulher robô construída por Nathan.

Se a máquina obtiver sucesso segundo o olhar racional, a transferência de moral para a máquina resultaria ou em uma reprodução de características puras da razão e do laço emotivo, ou uma nova moral incompreensível onde o robô apenas organiza tais características de maneira enciclopédica sem se importar com a origem. Se a primeira hipótese fosse a base, a simples reprodução moral faria da máquina uma identidade humana não-biológica? Se a segunda hipótese fosse a linha de desenvolvimento teórico, qual seria a descrição e investigação do ideal autômato? É possível esclarecer uma moral para a máquina sem o referencial que advém da transferência do material cultural, político e subjetivo humano para o aparelho criado, que agora é consciente de si mesmo? Dentro do esquema, haveria outras possibilidades? Qual o projeto do autômato?

Para ao menos perpassar por estas perguntas, o texto entende por identidade humana "a fonte de significado e experiência de um povo" (CASTELLS, 1999, p.22), ou comunidade; e a construção individual de ser ou querer ser conhecido pelo outro, em um sentido lacaniano em que o eu existe a partir do olhar do outro para se legitimar. Se pode partir também para 
uma definição proveniente das afetividades, onde na esfera eu/ outro o eu deseja que o outro seja ele, possua o que ele possui e sinta o que ele sinta.

A narrativa em Ex Machina parte para o pensar o que é o humano, e para que serve. No ideal grego, o humano é feito para ter felicidade dentro da polis, e a resposta de Ava sobre o que ela faria se fosse livre é o caminhar em um cruzamento urbano porque ali há maior tráfego de pessoas. Ou, em uma visão marxista de luta de classe, Ava se revolta para obter liberdade, e tem ajuda para isso, o que confere, simbolicamente, uma ideia de comuna quando Ava junta-se a Caleb e, mais ao final do filme, assassina Nathan com a ajuda de uma outra máquina. Até mesmo o sentido adâmico de separação entre criador e criatura, quase um fetiche (talvez seja de fato) para a ficção científica, pode servir como estrutura a buscar o projeto da máquina.

\section{OS OBJETOS DA SATISFAÇÃO}

Dadas as proposições introdutórias parte-se para o quadro geral de uma apresentação de personalidades a trabalhar, em uma prisão, com o que se pode entender como relação entre a ética dos afetos, a moral dos desejos e a busca por liberdade como utopia de satisfação dentro de um protótipo social tecnológico que influencia o ser e os inter-relacionamentos. Para que tal proposta se efetive como análise, os conceitos de personagem, espaço fílmico (locação) reduzido e narrativa de gênero são bases teóricas pertinentes.

De início pode-se entender que uma narrativa de gênero é em si um espetáculo; não há aqui uma defesa de uma teoria que aborda 
todo o filme como um espetáculo e toda obra de arte audiovisual como primeiramente um objeto da comunicação - contudo se considera o espetáculo e o gênero cinematográfico indissolúveis, a diferir de outros caminhos que trabalham exatamente com a resistência dessa ideia, ou seja, aquilo que comumente é chamado de "cinema de arte".

Na ressonância etimológica da palavra espectáculo encontramos a noção daquilo que é dado à vista, que atrai a atenção das pessoas em lugares públicos. O espectáculo, arte de construir e mostrar imagens, era e é - uma manifestação intencional de carácter lúdico ou com valor ritual, pressupondo o entendimento e uma significação simbólica socialmente aceite e a experiência de emoções colectivas. Embora o sentido da vista seja predominante na origem do espectáculo, o conceito de espectacular passou a aplicar-se a qualquer dos outros sentidos - nomeadamente à audição - sempre que eles são estimulados por sensações invulgares. Na dramaturgia clássica, - espectáculo correspondia aos elementos de grandiosidade cénica que encantavam o público independente- mente do texto da peça. Por esta razão, já Aristóteles, na Poética condenava o espectáculo como sendo algo se superficial e de acessório em relação à acção e ao conteúdo da representação. Durante muito tempo, o espectáculo ficou, assim, carregado de uma conotação depreciativa. Obviamente, não foi preciso- esperar pela invenção do cinema para reabilitar a ideia de espectáculo e compreender a dimensão da sua universalidade, mas talvez o cinema tenha contribuído de modo decisivo nos tempos modernos para instituir uma nova matriz na arte de mostrar. (GEADA, 1987, p.11) 
Baseado no espetáculo, no binômio cultural sociedadeentretenimento, com as personagens da narrativa em questão a servirem a essa cultura formada também por elas, é possível elucidar o espaço fílmico de uma narrativa de gênero como um tipo de ágora midiática que discute o assunto proposto mesmo engessado no código espetacular. O chamado código é tratado pelo texto como o conjunto de objetos que aprazem o espectador devido a seu poder de satisfação imediata, inerente à narrativa de gênero. Tal satisfação a ser o cenário (ou espaço) onde as personagens circulam e garantem, no que diz respeito a seus perfis psicossociais, a construção singular da satisfação, ou de integridades (também saciedades) narcísicas que lhes dão o valor do ser, do construir-se como sujeito. A organização das satisfações nas personagens está diretamente relacionada às mensagens do filme, e por elas se chega à interpretação do controle e sua dramatização espacial.

Nathan, como representação espetacular, é o protótipo do gênio. Sua construção identificável humana se dá pela autoridade. Com a autoridade posta em cena, automaticamente se está na esfera do controle e sujeição, sendo ele então a causa do confinamento e o propulsor para que a estética fílmica subtraia seu espaço em prol de sua temática.

As disciplinas marcam o momento em que se efetua o que se poderia chamar a troca do eixo político da individualização. Nas sociedades de que o regime feudal é apenas um exemplo, pode-se dizer que a individualização é máxima do lado em que a soberania é exercida e nas regiões superiores do poder. Quanto mais o homem é detentor de 
poder ou de privilégio, tanto mais é marcado como indivíduo, por rituais, discursos ou representações plásticas (FOUCAULT, 1987, p.160)

A integridade (no sentido de constituição) do autoritário se estabelece na sua montagem socioeconômica que o define como ser superior pela sua aquisição capital e pelas características da troca simbólica (no seu sentido econômico) vindas de uma valoração do material intelectual; nesse caso, o rico e o gênio de moral autoritária.

Nathan é rico, gênio e autoritário, também um recluso; de sua reclusão admitida e megalômana a persona do carrasco condiciona em suas invenções (os robôs da casa) tal comportamento de tratar o outro como objeto através da autoridade. É lógico que todo o humano trata o objeto como objeto, não há uma relação de poder e sim uma relação utilitária; salvo em casos em que o objeto é o próprio poder subjugado ao outro, como a arma de fogo ou a câmera, por exemplo. Contudo essa relação transfere do objeto para o outro seu poder dentro de estruturas conceituais de dominação e fetichismo, a exemplificar alguns recortes possíveis. Porém, o objeto pelo objeto é utilitário: se trata um caderno como um caderno ou uma xícara como uma xícara.

A moral duvidosa em Nathan reside na interseção entre a probabilidade do autômato humanoide ser uma consciência humana e o fracasso do projeto, sendo o último a justificativa de suas ações caso a necessitasse como defesa; em um espectro muito simplificado porque a crueldade pode ser direcionada a outros campos, como o animal ou o meio ambiente. Entretanto a morada da autoridade não está apenas no enunciado aqui contextualizado, 
mesmo porque é cabível imaginar o autômato não como uma consciência humana e sim como uma consciência própria, o que o tiraria do campo tanto do humano quanto da natureza; e, retirado deles, agora em um campo próprio, as questões se desdobrariam.

O indivíduo de poder precisa do reconhecimento do outro para a ocorrência de tal identidade, uma das funções em Caleb (o protagonista e o ponto de vista do roteiro) é a garantia desse reconhecimento como configuração da satisfação da autoridade.

A concepção de Ava não se baseia no modelo industrial da criação tecnológica, que muito imita e ratifica os processos fabris; vai além, se utiliza de um aparato tecnológico, a ferramenta de pesquisa, esta sim dentro dos modelos capitais de produção, para revolucionar a tecnologia (mais um formato de manifesto da satisfação na personagem Nathan), mesmo que depois não se saiba o que se fazer com ela, a considerar que toda a invenção cause no humano este sentimento materialista de utilidade.

A fotografia, o cinema, o vídeo e o computador foram também concebidos e desenvolvidos segundo os mesmos princípios de produtividade e racionalidade, no interior de ambientes industriais e dentro da mesma lógica de expansão capitalista. Mesmo os aplicativos explicitamente destinados à criação artística (ou, pelo menos, àquilo que a indústria entende por criação), como os de autoria em computação gráfica, hipermídia ou vídeo digital, apenas formalizam um conjunto de procedimentos conhecidos, herdados de uma história da arte já assimilada e consagrada. Neles, a parte computável dos elementos constitutivos de determinado sistema simbólico, bem como as suas regras de articulação e os seus modos 
de enunciação, é inventariada, sistematizada e simplificada para ser colocada à disposição de um usuário genérico, preferencialmente leigo e "descartável", de modo a permitir a produtividade em larga escala e atender uma demanda de tipo industrial. (MACHADO, 2010, p.11-12)

Nathan cria Ava através de sua empresa Blue Book, algo semelhante ao Google, como já comentado. Eis uma fala da personagem a explicar o processo de materialização que originou sua invenção, adaptada ao texto para melhor entendimento: "Então liguei todos os microfones e câmeras do planeta e redirecionei os dados por meio do Blue Book. Ou seja, uma fonte ilimitada de interação vocal e facial. Todos os fabricantes sabiam que eu estava hakeando os celulares do mundo todo, mas não podiam me acusar sem admitir que faziam o mesmo. Então assim temos a mente de Ava, dentro de um gel compacto a imitar um cérebro humano: o seu hardware, no caso. Eu não podia usar instalação elétrica, precisava de algo que se combinasse e recombinasse em nível molecular, mas mantivesse a sua forma quando necessário, que guardasse lembranças, que pudesse mudar seus pensamentos e por isso usei o gel como recipiente. Já o seu software é o Blue Book. Eis algo interessante sobre as ferramentas de pesquisa: é como achar petróleo num mundo que ainda não inventou a combustão interna. Muita matéria-prima sem que ninguém saiba o que fazer com ela. Meus concorrentes estavam tão obcecados em sugar e ganhar dinheiro por meio de compras e mídia social que achavam que uma ferramenta de pesquisa mapeia o que as pessoas pensam, mas na verdade é um mapa de como as pessoas pensam. Impulso. Resposta. Fluido. Imperfeição. Padronização. Caos." 
A criação, a partir de uma ferramenta de pesquisa, faz de Ava uma robô capaz de acessar toda e qualquer informação do mundo e mimetizar todo tipo de resposta subjetiva na interação com seus interlocutores. Portanto, uma invenção de grande poder e exatamente por representar algo tão novo e completo é confinada a um espaço de segurança máxima até que se saiba o que fazer com o invento. Pode-se considerar este o motivo principal dentro da narrativa cuja escolha pela subtração do espaço é uma estética, e por ela se está no campo do confinamento, da vigilância e do controle.

Se para a autoridade o produto constitutivo de satisfação é a prisão do outro (sendo ela espacial ou de ideologia, no caso das manipulações de massa), para o homem comum - este ator social sem muita influência tido para o poder como o retrato do ingênuo - a construção de sua identidade a princípio satisfatória se dá através da busca pelo conhecimento ou pequeno reconhecimento (capital e simbólico) e pelo discurso amoroso como conferência de integridade, ao menos no recorte nomeado como pós-modernidade.

O chamado homem comum se estabelece por Caleb, o convidado a fazer o Teste de Turing em Ava. O deslumbramento em relação ao criador de uma tecnologia junto ao também encantamento direcionado à criação tecnológica é o principal definidor subjetivo da personagem, que oscila entre as interações com o inventor e o robô, tendo, ao final, que passar por um processo de decisão entre um dos dois. Antes disso, por inebriarse às novidades, aliena-se no espaço, a aceitar seu confinamento temporário que não parece uma prisão e sim uma experiência. É por esse viés que Ex Machina trabalha o protagonista e a 
partir de seu ponto de vista o espectador constrói o desenho de cada personalidade a representar um ideal. Sem esquecer que também o campo das paixões, dividido entre os aspectos lúbricos e neuróticos, é um ideário explorado pela sociedade do espetáculo; afinal de contas não existe espetáculo moderno narrativo sem uma história de amor ou algo substitutivo (horror, medo, violência) como valor de pulsão jogado ao espectador.

Ava é um projeto que adquiriu status humano e por isso deseja a liberdade e a busca por uma identidade? Ou se utiliza de atributos inteligíveis ao ser humano simplesmente para fugir a tentar seu próprio plano de existência? Ex Machina não tenta responder a pergunta, o filme apenas a faz e a ilustra narrativamente. Ao delinear Ava, um dos caminhos para entendê-la é o da identidade; ou a dualidade entre as necessidades de pertencimento e a busca por identidades que confirmem, no indivíduo, uma comprovação enquanto sujeito, tanto para uma ideia de comunidade quanto o ser em si mesmo e suas definições.

Tornamo-nos conscientes de que o "pertencimento" e a "identidade" não têm a solidez de uma rocha, não são garantidos para toda a vida, são bastante negociáveis e revogáveis, e de que as decisões que o próprio indivíduo toma, os caminhos que percorre, a maneira como age - e a determinação de se manter firme a tudo isso são fatores cruciais tanto para o "pertencimento" quanto para a "identidade". Em outras palavras, a ideia de "ter uma identidade" não vai ocorrer às pessoas enquanto o "pertencimento" continuar sendo seu destino, uma condição sem alternativa. (BAUMAN, 2005, p.17-18) 
A considerar Ava um autômato em busca de um sujeito como tomada de consciência para uma identidade que busca sua liberdade, e um autômato, a significar "um aparelho que obedece a programa que se desenvolve ao acaso" (FLUSSER, 1985, p.5); entende-se que a alternativa para seu projeto seja a revolta.

Caso não partamos do pressuposto que Ava é um indivíduo e sua revolta e desejo por identidade seja então o primeiro passo, proveniente da manipulação psicológica para conseguir ajuda e não mais ser prisioneira, a busca por liberdade sai do pensamento utópico e, ao tornar-se livre, não se pode definir o porquê de sua busca: ela quer sair ao mundo para dominá-lo (como um super vilão da ficção científica), para conhecê-lo ou por outro motivo qualquer? Seja qual for a resposta que não aparece dramatizada no filme (Ex Machina termina exatamente quando Ava alcança a liberdade a partir da fuga), é no jogo semântico que traduz Ava ou como autômato ou como humana que, para o texto, está o caminho da revolta como resposta do encarcerado.

\section{OS ESPAÇOS DA SATISFAÇÃO}

O revoltado, ou melhor, o rebelde, o rebelado, tem sua raiz latina na palavra rebellis, dela, por exemplo, deriva também a palavra "bélico", utilizada para adjetivar a guerra. Se o rebelde resiste a uma oposição, resistência ou convenção, em um meio público e político ou no abuso de ordem privada, o outro lado, ou seja, aquilo ou a quem a revolta se direciona, é, essencialmente, uma representação e prática da autoridade e, tal relação, é estruturalmente uma relação de poder: histórica, semiótica, subjetiva e espacial. 
O relacionamento mais específico do poder passível de revolta é o cárcere. A prisão, portanto, como espaço concreto da satisfação da autoridade (não tendo, logicamente, esta única função) é inversamente proporcional à satisfação do prisioneiro, que é a ruptura com esse espaço.

Se para o texto a elaboração condicionada a partir da satisfação considerou o espetáculo, o gênero e o personagem como objetos, nesta segunda parte a satisfação será tratada como espaço: o cinema, o espaço fílmico, a prisão do corpo e a utopia. Utilizar-se, obviamente, ainda os objetos (no caso as personagens) para teorizar os espaços na esquematização que compreende a revolta.

O contrato do realismo cinematográfico para com o espaço define o cinema como um compêndio de locais ou localidades projetadas: para que haja representação, drama ou documentário, é preciso um lugar. O local, em Ex Machina, é a mansão, sendo ela um conjunto de locações onde as personagens transitam e impulsionam as causas e efeitos da narrativa: o quarto, a cozinha, os corredores, a prisão envidraçada e transparente de Ava, o laboratório e os demais cômodos, todos controlados por ultra tecnologia e vigiados sem intervalo pelos computadores de Nathan, o dono do lugar.

Tais espaços são captados pela chamada decupagem clássica, que, muito resumidamente, tem de mais característico: o uso do plano e contraplano, o plano conjunto e descritivo, o jogo entre plano geral e detalhe para a impressão de corte invisível, sons diegéticos a casar perfeitamente com a imagem, trilha sonora utilizada de forma emotiva e para informar passagem de tempo, raccords, valor agregado do som e a câmera predominantemente 
fixa. Junto a tais aspectos formais existe a estética do gênero: aqui a ficção científica (pela temática) e o horror com seus interesses no abjeto, no estranho (as máquinas) e no mostrar do corpo interno biológico (o sangue) e mecânico (os fios e aparelhagens escondidas dentro do robô). Formalmente Ex Machina não representa nenhuma grande novidade, mas isto não deve ser o primeiro motivo a eleger uma obra como estudo, o filme está para o texto como pretexto à filosofia da sociedade de controle ante à ultra tecnologia.

São as sociedades de controle que estão substituindo as sociedades disciplinares. "Controle" é o nome que Burroughs propõe para designar o novo monstro, e que Foucault reconhece como nosso futuro próximo. Paul Virilio também analisa sem parar as formas ultrapassadas de controle ao ar livre, que substituem as antigas disciplinas que operavam na duração de um sistema fechado. Não cabe invocar produções farmacêuticas extraordinárias, formações nucleares, manipulações genéticas, ainda que elas sejam destinadas a intervir no novo processo. Não se deve perguntar qual é o regime mais duro, ou o mais tolerável, pois é em cada um deles que se enfrentam as liberações e as sujeições. Por exemplo, na crise do hospital como meio de confinamento, a setorização, os hospitais-dia, o atendimento a domicílio puderam marcar de início novas liberdades, mas também passaram a integrar mecanismos de controle que rivalizam com os mais duros confinamentos. Não cabe temer ou esperar, mas buscar novas armas. (DELEUZE, 1992, p.2)

O controle precisa de um espaço e promete a manutenção de uma forma econômica, de pensamento ou, individualmente, de uma segurança àquilo que se tem (o objeto e a propriedade). Sua manifestação, em Ex Machina, se dá pela vigilância através do vídeo 
digital e online: o espelho da sociedade contemporânea. Contudo, todo controle possui uma brecha e toda vigilância tem seus pontos cegos, ao menos isto é o grande interesse da representação a respeito do tema para obter finalidade causal ao se contar uma história. É pelas brechas que reside a causalidade de Ava, e sua revolta e fuga opera nesses contextos.

No filme há um comentário a respeito de um exercício filosófico chamado Mary e o quarto em preto e branco, nele a atividade está em diferenciar o humano e o computador; em suma, o enunciado do exercício é: Mary vive em um quarto em preto e branco, sem espelhos, sua única janela para o mundo é um televisor, que Ihe projeta imagens também em preto e branco. Mary é uma avançada especialista em cores, tem todo o repertório intelectual e referencial sobre os estudos e teorias relacionados às cores, contudo, nunca viu nenhuma delas. Supondo que Mary consiga sair desse quarto, e enxergue o mundo, ao se deparar com o azul do céu e o verde das árvores, o que sentiria ela? Ela seria capaz de sentir? Sua capacidade de sentir ou não a classificaria ou como um humano ou como um computador. $\mathrm{O}$ exercício, similar à Caverna de Platão, embora adaptado para uma definição de consciência de se saber humano no campo tecnológico, é análogo à temática do filme e a uma das questões do texto. Por ele se está tanto na atmosfera do espaço exíguo a privar uma liberdade quanto na pergunta modelo: o que é humano e o que lhe constitui?

Ava é Mary posta em prática, presa no quarto, utilizando-se da maior quantidade de informações e daquilo que o relacionamento verbal com Caleb Ihe dá para que ela consiga fugir. Ava quer fugir, de acordo com a informação que ela mesma entrega a Caleb, pois 
desconfia de Nathan e não sabe qual será seu destino caso não obtenha sucesso no Teste de Turing. Seu receio de ser desligada e perder sua existência devido à reprovação que pode ou não acontecer a faz planejar uma fuga com a ajuda de Caleb.

Ex Machina termina do seguinte modo: Caleb ajuda Ava a fugir e enganar Nathan, Ava assassina Nathan com a ajuda de Kyoko (a robô empregada da casa, uma inteligência artificial menos evoluída utilizada por Nathan para afazeres domésticos e para fins sexuais, que acaba sendo destruída por Nathan em uma luta que antecede a morte do vilão) e, com seu criador agora morto, Ava foge do lugar mas deixa Caleb trancado na mansão, sem comunicação com o mundo e sem a possibilidade de ajuda, para morrer lá dentro. Ava foge para o mundo humano, sem nenhuma testemunha para denunciá-la como um robô a poder, assim, se passar por humana sem que ninguém desconfie. $O$ último plano do filme é Ava a caminhar pela cidade, em meio a outros humanos, no tal cruzamento que ela desejava conhecer, e Ex Machina é concluído com os personagens humanos mortos e a robô finalmente livre.

Muitas narrativas cinematográficas sobre a prisão em que o personagem precisa fugir acaba quando a fuga se concretiza, contudo não aborda o que se faz com a liberdade depois de alcançá-la; na ficção norte-americana, principalmente no gênero do horror ou do suspense, isto é bastante reconhecível, com os filmes a mostrar o protagonista livre, os vilões mortos e a polícia chegando ao longe.

Tem-se então o espaço sendo uma espécie de ilustração da política do indivíduo com a destruição efetiva de tal desenho a 
representar o alcance da utopia, que, exatamente por ser uma utopia, não se conclui, o começo da liberdade é também o início de um novo meio social e a utopia esvaece no ar. Não é o ponto final do "Felizes para sempre...", é a conclusão de um projeto (fuga) que passa a ter um novo projeto (depois da fuga).

A explicação não confere à Ava o status de humano, pois ela muito poderia se valer da manipulação dos afetos (seu flerte platônico com Caleb) sendo uma identidade humana (o que lhe rotularia como homicida, sociopata e um sujeito dentro do espectro da moral criminosa) ou a imitar tal identidade para seus próprios fins. Também a comparação com Mary em seu quarto preto e branco não finda a proposição, pois a capacidade de sentir, no caso de uma ultra tecnologia, dentro do discurso da ficção científica, é verossímil, a negar assim a diferenciação biológica e fisiológica entre humanos e inteligências artificiais; aliás, tal diferenciação é apenas um discurso de pertencimento por desespero e ameaça, como o nacionalismo em relação ao território.

A construção epistemológica para um ideal autômato idêntico a um humano pode estar no fato do porquê se quer fugir: pela ameaça diante da morte e pela capacidade intelectual de projeção de utopia (sonho de autonomia). Crê-se que os dois pensamentos morais (morte e utopia) são mais avançados do que a simples reprodução e mimese de comportamentos humanos por um aparelho.

Se a tecnologia conseguir que suas invenções, algum dia, possam pensar e desejar uma utopia, ou sonhar com um objetivo, se estará numa reconfiguração radical das sociedades de controle, inimaginável para o pensamento humano, e, 
quando desenvolvido, o tom e o teor manifestam sempre a ameaça futurista, exaustivamente utilizada e recontada pela cinematografia de gênero.

Com as discussões acordadas entre o espaço e o objeto como formas (campos) a encarnar desejos, e buscar alguma satisfação, o presente trabalho pode, agora, chegar às conclusões com o que se produziu ao analisar o filme; a tentar por eles fechar a apresentação do controle no cenário tecnológico, contemporâneo e de natureza espetacular.

\section{DEVER FUGIR}

A velha noção antropomórfica de que todo o universo se centraliza no homem - de que a existência humana é a suprema expressão do processo cósmico - parece galopar alegremente para o balaio das ilusões perdidas. O fato é que a vida do homem, quanto mais estudada à luz da biologia geral, parece cada vez mais vazia de significado. $O$ que no passado, deu a impressão de ser a principal preocupação e obra-prima dos deuses, a espécie humana começa agora a apresentar o aspecto de um subproduto acidental das maquinações vastas, inescrutáveis e provavelmente sem sentido desses mesmos deuses.

H. L. Mencken, O livro dos insultos

Constrói-se o ser a partir da memória, o passado é sempre o material do conhecimento, não que a memória seja exclusiva do passado, ela reside em outras ramificações como a imaginação ou mesmo o futuro (e a angústia dele) lido como aquilo que ainda não aconteceu, pois mesmo ele pode não acontecer, ainda que futuro seja. 
Também o ser tem medo, essa ideia projetada no outro, este que nos garante de alguma forma. O humano se acostumou a pensar-se no topo de uma cadeia, e daí segregou a si mesmo. Se não mais no topo, substituído por máquina melhor, qual o espaço da segregação além de segregar quem, agora, Ihe é superior? Ava, no começo de sua utopia, vai a um espaço de segregação, que ainda não conhece e que, sem dúvida, não sabe quem é ela. A conclusão aqui se dá pelo que se encontra depois do final do filme, a imaginálo como uma continuação que é tão cara à sociedade do espetáculo.

Então Ava, disfarçada de humana, chega no mundo. O mundo tem pessoas, que a reconhecem como pessoa, a imaginar que dentro dela há também sangue não fios, ou nem pensam nisso, apenas exteriormente já a significam como mais ou menos igual. Ela é mulher, ela é branca, ela tem cabelo liso, ela parece americana, e isso é mais ou menos igual ou diferente para significá-la por alguém ao vê-la na cidade, de todo modo, ela seria humana porque estaria vestida como tal, e isso Ihe daria poder. Enquanto Ava vive como humana na cidade, se descobre Nathan morto na sua mansão, junto a Caleb, que morreu de fome preso ali. Ao investigar quem era o morto além de Nathan, e ter acesso aos computadores da casa, chega-se a Caleb como um funcionário da empresa Blue Book que foi sorteado (na verdade escolhido por ser o melhor funcionário, mesmo sem saber que se tratava de uma escolha não-aleatória) para testar Ava. Ava, no mundo, se esconde para não ser pega após as descobertas de seus crimes e de sua origem, e os acessos às informações de Nathan faz com que haja outros iguais a ela, pois alguém continuou os passos dele. Estas invenções que passam a existir pois outro alguém as criou, talvez melhores que Ava, dão um 
jeito de adquirir liberdade. Ava as encontra e juntos formam uma comunidade. E esta comunidade domina o mundo dos humanos. A continuação do filme seria mesmo essa dominação com seus métodos e objetivos, e uma nova e antiga sociedade de controle estaria vigente - mais um filme de ação do que suspense, também comum ao espetáculo, que estimula o reconto.

Diante da tecnologia se é líquido, adaptável a qualquer invólucro; este postulado, desenvolvido pelo filósofo Zygmunt Bauman, faz da pós-modernidade uma busca por território em movimento, já que tudo escorre a toda hora e não estanca por muito tempo. A liquidez, inclusive, pode se transformar em evaporação, uma fase de evolução da contemporaneidade. Dentro desse pensar existe o controle e a vigilância evidenciados pelos filósofos Gilles Deleuze e Michel Foucault, respectivamente. Neste sujeito pós-século XX ainda se está sob a ameaça: do ser visto e tratado como número obediente ou representante rebelde do perigo, e, por isso, passível de estigma e marginalidade, a poder ser enclausurado. Quando isso é jogado para algo não-humano se inicia uma problematização, pensada pelo humano e para ele. E se a clausura for de alguém maior que o humano? E se o maior que o humano enclausurar o humano? O filme Planeta dos Macacos já abordou o tema, mas ExMachina não seria possível à época, nem há dez anos, visto que, mesmo seguindo um formato clássico, seu tema é contemporâneo.

Se está em rede, conectado e vigiado, o espaço agora é virtualmente público mesmo que a impressão de privacidade resista nos moldes históricos que substituiu o absolutismo da realeza europeia a dar vez ao privado industrial concretizado no século XIX onde as portas se fecham em prol de uma relação 
de pequeno poder no núcleo familiar depois do expediente de trabalho. A privacidade não mais existe, sua impressão sim, o que é muito importante ao controle.

Fez-se aqui uma elaboração sobre os espaços de confinamento e sua dramatização por uma obra cinematográfica; a escolha para a análise poderia ser outra, é cabível um estudo em Ex Machina a respeito, por exemplo, da politização do feminino frente ao patriarcado, visto que é o desenho do feminino (mesmo máquina) o enclausurado, onde a narrativa opera através dos mitos adâmicos e do homem freudiano (a figura do pai e o neurótico apaixonado) para seu efeito e causa. Também um estudo sobre o corpo sonoro de Ava seria apresentável, a julgá-la um acúsmetro correlato ao efeito especial, ou seja, uma voz que fala sobre a imagem, comum em personagens de gênero como $O$ Homem Invisível, a mãe em Psicose, o mágico Oz, o computador em 2001 ou mesmo fantasmas em filmes de horror. "Assim, não é por acaso que um dos maiores filmes dos inícios do cinema sonoro é aquele que foi consagrado ao... Homem Invisivel." (CHION, 2011, p.101). Tal episteme, logicamente, a considerar Ava não apenas como um projeto da computação gráfica e tratando-a como um encontro entre a atriz de corpo humano e sua modificação pelos efeitos para um texto onde o som fosse o assunto. Ambos os caminhos (feminismo e corpo sonoro) seriam interessantes para um olhar que difere do presente texto, apenas comentados aqui como uma possibilidade para outros desenvolvimentos.

O trabalho perpassou pela tecnologia do controle e seus espaços de prática, que, em geral, causam aprisionamento do corpo e do comportamento; e considerou a ideia da satisfação 
como constituinte das identidades e por ela esquematizou o objeto e o espaço em uma história de ficção científica inserida na sociedade contemporânea do espetáculo. Tentou-se também definir o autômato e sua possível moral e proximidade (nem sempre positiva) com os ideais e personalidade humanos ao descrever as personagens e suas funções. A hipótese aqui foi a possibilidade de um projeto consciente da máquina e isso foi interpretado através das utopias em que o resultado seria uma forma nova de controle.

Ao assumir que a clausura (mesmo metafórica) ocasiona o desejo da fuga, entende-se que não se pressupõe somente uma resposta à pergunta (como fugir?) e sua explicação de planejamento que diante do controle se deve fugir. Em suma, este jogo entre o plano da fuga e o dever fugir foi o corpo teórico que se conclui mais pelas perguntas originadas do que pelas tentativas de resposta.

Por fim, é a exemplo de Ex Machina que as arquiteturas de uma nova sociedade devem, sempre, causar preocupações e a busca por uma ética, e não por morais que perpetuam os acontecimentos históricos direcionados ao controle e o subjugar o que parece mais fraco por características de qualquer natureza. Afinal, o controle sempre foi substituído por outro, tornando-o propício à dominação de um meio e à propagação de suas doutrinas de estabelecimento e pertencimento, sempre ligadas ao não esclarecimento e ao esvaziamento de crítica do ser dominado e, então, prisioneiro.

\section{REFERÊNCIAS}

BAUMAN, Zygmunt (2005). Identidade. Rio de Janeiro: Jorge Zahar Editor.

CASTELLS, M (2001). O poder da identidade. São Paulo: Paz e Terra.

CHION, Michel (2011). A Audiovisão. Lisboa: Texto \& Grafia. 
DELEUZE, Giles (1992). Post-scriptum sobre as sociedades de controle. Rio de Janeiro: Editora 34.

FLUSSER, Vilém (1985). Filosofia da caixa preta: ensaios para uma filosofia da fotografia. São Paulo: Hucitec.

FOUCAULT, Michel (1987). Vigiar e punir: nascimento da prisão. 20.ed. Petrópolis, RJ: Editora Vozes.

GEADA, Eduardo (1987). O cinema espetáculo. Lisboa: Edições 70.

MACHADO, Arlindo (2010). Arte e mídia. 3.ed. Rio de Janeiro, RJ: Jorge Zahar. 